\title{
Presumed consent: a problematic concept
}

\author{
AAMIR M JAFAREY ${ }^{1}$, FARHAT MOAZAM ${ }^{2}$
}

Centre for Biomedical Ethics and Culture, Karachi 74200 PAKISTAN e-mail: 'aamirjafarey@gmail.com ²famoz@mindspring.com

In her article, Jyotika Kaushik addresses an important issue, that of the increasing shortage of kidneys available for transplantation worldwide (1). As a solution for India, Kaushik favours the introduction of the "presumed consent" system to allow retrieval of organs from recently deceased persons. In this system, unless an individual has specifically expressed, in writing, during her/his lifetime, that he/she is unwilling to donate an organ following death, his/her organs can be routinely harvested by healthcare professionals for transplantation into others. In our commentary we examine some of the arguments put forward by the author in support of presumed consent, and discuss ethical, professional and social problems connected to the use of this system as a way to address the scarcity of transplantable organs. However, we will begin by first highlighting what we consider to be a critical factual error in the article.

The author states that it is "dissatisfaction with the current regime of informed consent" that has "led to progressive deepening of the imbalance between the need for, and supply of, solid organs for transplantation". In reality, the widening gap between the supply and the demand for organs is a far more complex issue, and it has occurred despite a steady global rise in the numbers of living and deceased donations. Technological advances, sophisticated surgical skills, and progressive improvement in immunosuppressive regimens have enlarged the pool of individuals who are now accepted as "transplantable". Patients not considered suitable candidates for kidney transplantation only a few years ago - infants and children, the very old, those with co-morbid factors such as diabetes, patients with more than one previously failed kidney transplantation - are now routinely offered this procedure.

In addition, the gap between the number of kidneys available for transplantation and the number of patients waiting for a transplant is widening for a number of reasons. These include longer life spans leading to age- related illnesses, obesity and a concomitant increase in the incidence of diabetes worldwide, and the failure to focus on prevention of renal diseases, all of which are also contributing to greater numbers of people developing end-stage renal disease. Without appropriate attention to some of these factors, no measures can ever be successful in providing sufficient kidneys to meet the rising need $(2,3)$.

\section{Is it really "consent"?}

The term "presumed" consent is ethically problematic. As defined, it is in direct opposition to the moral premise on which "consent" rests within healthcare delivery systems. It also negates the ethical basis of the relationship between healthcare providers and the public. Taking and giving consent to donate an organ, whether during an individual's lifetime or to occur following his/her death, is an ethical process; it involves a dialogue in which all relevant information is provided to the potential donor, complete comprehension is ensured, and this is followed by an un-coerced decision by the individual to either donate an organ or refuse to do so.

To therefore "presume" by default that we have "consent" to remove organs from a deceased person because there is no prior statement from him/her against such an action cannot be said to meet the universal criteria for ethical consent as understood by the medical profession. A "presumed consent" would be analogous to the practice of taking the silence of a young woman as her consent to marry a 75-year-old groom. This term can be argued, with some justification, to be an example of an oxymoron along the lines of "honour killing" or "jumbo shrimp".

\section{Negative impact on the profession}

Transplanting an organ is undertaken by a team of healthcare professionals and can be among the most lucrative procedures for physicians and staff of a hospital. Legal sanction allowing physicians to routinely remove organs from those who die in hospital without a pre-mortem statement forbidding this can have profound negative repercussions on the medical profession, and on a physician's relationship with patients and family members. It is not far-fetched to imagine growing public suspicion that physicians, instead of doing everything they can to save the lives of the critically ill, are more interested in obtaining as many kidneys as they can following death.

Such perceptions would be far more pronounced among the poor and the powerless in society. This fact has also been documented in African American communities in the USA and is reflected in their attitude to organ donation (4). It should be noted that while the dominant western physician-patient paradigm is of a "contractual" relationship between "equals", the hierarchical systems and power differentials that exist in South Asian societies define the same relationship as primarily a fiduciary relationship in which trust/faith (bharosa in Urdu, vishwas in Hindi) between the two parties is central. In a system of presumed consent for routine removal of organs, this trust between patients and healthcare providers would be the first casualty, with far-reaching consequences for healthcare providers and their relationship with society. 


\section{The patient, the family, and the physician}

The centrality of the family in major human life events - birth, illness and death - is a universal phenomenon even though the level of family involvement may vary from one society to another. In most Asian societies, major decisions are taken collectively by members of the family (5). Presumed consent, on the other hand, is based on an individual's right to prohibit harvesting his/her organs following death and the right of the physician to proceed to do so in the absence of this prohibition. The family plays no role in this decision making dyad. But abstract "text" or law is different from the living "context" of a situation. Physicians faced with distraught, grieving families opposed to removal of organs from a recently deceased son or daughter will find it impossible to counteract their wishes. The inadvisability of doing so on moral and compassionate grounds, and fear of the negative impact on the image of the physician involved, would outweigh the legal cover for the act. In countries such as the USA, even when a deceased has given prior written permission via a donor card to donate organs following death (called the "opt in" system in contrast to the "opt out" or presumed consent system), physicians do not harvest the organs if there is opposition from the family.

Kaushik herself acknowledges the importance of family sentiments when discussing presumed consent systems in European countries, including Spain, which has one of the most successful deceased donor programmes in the world. The success of the Spanish programme is largely due to substantial financial and manpower investment in intensive ongoing public education and engagement. As a result of this the number of families who oppose deceased donation has decreased dramatically. Nevertheless, as Kaushik notes, the family of the deceased is allowed the last say if found unwilling to allow organ harvesting. To do otherwise would jeopardise public goodwill and trust without which no organ donation programme of any kind can ever succeed.

Kaushik argues that a legal statement prohibiting use of one's organs following death would help to "empower" the individual, but this is an individualistic view which may not hold true within the collective realities of societies such as ours. The average citizen in countries with high illiteracy rates seldom makes an elaborate will indicating distribution of possessions following death. Death is not considered a suitable topic for discussion, and it is taken for granted that the family knows best and will take care of the formalities. In this cultural milieu, it is unlikely that an individual will be interested or motivated enough to draw up a document indicating the manner in which his/her organs should be dealt with; it is even less likely that this will be regarded as an act of empowerment.

\section{Organs as "goods"}

The death of a member of a family is not perceived merely as a medical or legal event by the bereaved family, but one that is imbued with emotional, psychological, and religiously symbolic meaning. The process of mourning and coming to grips with the loss of a loved one involves customs and religious practices that are intimately connected with how the body of the deceased must be dealt with (6). These are all the more pronounced in traditional family-centred societies.
The system of presumed consent, on the other hand, rests on a philosophical, legal premise that following death, organs are "goods" that can be used for the benefit of society, reducing them to objects of utility not too different from shoes and clothes left behind by the deceased.

Kaushik employs the argument of a "social contract" and positive duties owed to others in society to support a system of presumed consent, but worries that family resistance can jeopardise obtaining organs from the deceased. Logically, it seems to us that her arguments about a social contract and the duty to address the needs of society are more in tune with employing the conscription model as a solution to kidney shortages. This model does not require the involvement of the individual or family at any point and allows organs to be routinely removed from the deceased for transplantation into others. The author does not advocate conscription as a mode of organ procurement because she is concerned about the potential negative effect on public perceptions. But in our opinion, this concern is equally valid for a system of presumed consent which, in societies such as India's, is liable to end up with the body parts of the least-advantaged being harvested for the benefit of the most affluent.

\section{Where we agree}

Having said this, we are in complete agreement with the author when she stresses the need for greater awareness and education of the general public about the need for increasing organ donation, both from the living and the deceased. To increase the latter in countries such as ours, we believe we must aim for efficient "opt in" models in which increasing numbers of citizens, in consultation with their families, register their informed, voluntary, consent for donation of organs following death. Kaushik is also correct in pointing out the importance of sound infrastructures to develop successful deceased donor programmes.

To make all this happen requires collective efforts by the medical and legal professions, media, members of civil society and the government. Without initiating concrete steps and continuing hard work, it is highly unlikely that we can reduce the deficit of organs. In fact, attempts to legally enforce presumed consent, or any other system for that matter, before preparing the ground, could alienate the public, erode their trust in the medical profession, and impact the organ transplantation endeavour in profoundly negative ways.

\section{References}

1. Kaushik J. Organ transplant and presumed consent: towards an "opting out" system. Indian J Med Ethics. 2009 Jul-Sep; 6(3): 149-152.

2. Abouna G. Organ shortage crisis: problems and possible solutions. Transplant Proc. 2008 Jan-Feb; 40(1): 34-8.

3. Chugh KS. Jha V. Problems and outcomes of living unrelated donor transplants in the developing countries. Kidney Int. 2000; 57(Suppl 74): S131-S135.

4. Siminoff LA, Burant CJ, Ibrahim SA. Racial disparities in preferences and perceptions regarding organ donation. J Gen Intern Med. 2006 Sep; 21 (9): 995-1000.

5. Farhat M. Families, patients and physicians in medical decisionmaking: a Pakistani perspective. Hastings Cent Rep. 2000 Nov-Dec; 30(6):28-37.

6. Fox Renee C. Organ transplantation: sociocultural aspects. In: Essays in medical sociology: journeys into the field. New Brunswick, New Jersey: Transaction Books; 1988: p.115-21. 